\title{
ANÁLISE DA QUALIDADE MICROBIOLÓGICA DO CALDO DE CANA COMERCIALIZADO EM UM MUNICÍPIO DA REGIÃO OESTE DO PARANÁ
}

\author{
Greice Sueli Gassen, Leyde Daiane de Peder, Claudinei Mesquita da Silva \\ Centro Universitário da Fundação Assis Gurgacz - FAG, Curso de Farmácia. E-mail: greh greice@hotmail.com
}

\begin{abstract}
RESUMO
O caldo de cana é uma bebida de baixo custo e de sabor agradável, devido a isso apresenta grande aceitação pelo consumidor. No entanto, a maioria dos vendedores ambulantes que comercializa esse alimento não possui condições higiênico-sanitárias adequadas para garantir um produto com qualidade, tornando o mesmo uma possível fonte de transmissão de doenças. Tendo isso em vista, o objetivo do presente estudo foi analisar a qualidade microbiológica de amostras de caldo de cana comercializadas no município de Cascavel-PR. Para tanto, realizou-se a determinação de coliformes totais e coliformes termotolerantes de 30 amostras de caldo de cana de vendedores ambulantes localizados em diversos pontos do município. Destas, $20(66,6 \%)$ apresentaram crescimento bacteriano (presença de coliformes termotolerantes) acima dos padrões legais vigentes para a comercialização da bebida. Diante disto, concluímos que o caldo de cana comercializado pela maioria dos comerciantes que atuam no município de Cascavel-PR pode ser considerado inadequado para o consumo.
\end{abstract}

Palavras-chave: Cana-de-açúcar, análise microbiológica, segurança alimentar, coliformes.

\section{Analysis of cane juice of microbiological quality marketed in a city in the Paraná west region}

\begin{abstract}
Sugarcane is an inexpensive drink and pleasant flavor, due to its high acceptance by the consumer. However, most vendors who sells that food doesn't have adequate sanitary conditions to guarantee a good quality product, making it a potential source of disease transmission. Keeping this in view, the aim of this study was to evaluate the microbiological quality of sugarcane juice samples commercialized in the city of Cascavel-PR. To this aim, there was the determination of total coliforms and fecal coliforms of 30 sugarcane samples from vendors located in various parts of the city. Of these, $20(66.6 \%)$ had bacterial growth (presence of thermotolerant coliform) above the statutory standards for the marketing of the drink. In conclusion, sugarcane juice sold by most traders operating in Cascavel-PR can be considered inappropriate for consumption.

Keywords: Saccharum, microbiological analysis, food supply, coliforms.
\end{abstract}

\section{INTRODUÇÃO}

O caldo de cana é um produto altamente nutritivo, de sabor agradável e de baixo custo. É comumente comercializado nas ruas por vendedores ambulantes, os quais possuem moendas para a extração do caldo. A maioria desses vendedores não possui instalações compatíveis com a atividade exercida, frequentemente sem as condições higiênicosanitárias necessárias à manipulação de alimentos $^{1}$.
Do ponto de vista microbiológico, a canade-açúcar possui grande quantidade de microrganismos em seus colmos, raízes e folhas, o que a torna um alimento propício para o desenvolvimento de bactérias ${ }^{2}$, no entanto, a maior contaminação do caldo de cana parece originar-se nos processos de sua extração. A comercialização de caldo de cana-de-açúcar tem se mostrado bastante precária, devido principalmente, à falta de práticas higiênicosanitárias adequadas nas etapas de despalhamento, descascamento e corte da cana. 
Geralmente, os processos citados são realizados com instrumentos inadequados para manipulação de alimentos, como foices e facas não higienizadas e sanificadas adequadamente ${ }^{3}$.

No entanto, a quantidade desses microrganismos deve ser controlada para evitar uma possível contaminação dos consumidores. Dessa maneira, a manutenção da qualidade microbiológica do caldo de cana consumido pela população segue Resolução da Diretoria Colegiada (RDC) 12/2001, a qual define os padrões microbiológicos para análises de alimentos, classificando o caldo de cana como um suco in natura ${ }^{4}$.

Sabendo tanto da importância das condições higiênico-sanitárias do ambiente, quanto da prática dos manipuladores envolvidos na extração do caldo de cana, o presente estudo teve como objetivos analisar a qualidade microbiológica desse alimento e avaliar as condições higiênico-sanitárias em que são produzidos e comercializados por ambulantes nas ruas do município de Cascavel-PR.

\section{METODOLOGIA}

Foi realizado um estudo transversal e experimental, tendo sido analisadas 30 amostras de caldo de cana de diferentes ambulantes que atuam em diferentes bairros no município de Cascavel-PR. As coletas aconteceram no mês de outubro de 2015.

O município de Cascavel-PR (24은 57' 21" S, 53 27' 19" W), está localizado na região Oeste do Paraná e possui uma área territorial de $2.100,831 \mathrm{~m}^{2}$. Possui uma população de 312.778 habitantes, conforme estimativa do Instituto Brasileiro de Geografia e Estatística (IBGE) ${ }^{5}$.

As coletas foram realizadas em frascos plásticos estéreis com capacidade para $300 \mathrm{ml}$, com tampa de rosca. As amostras foram acondicionadas em uma caixa térmica, com gelo em gel e encaminhadas a um laboratório analítico do mesmo município. Foram realizadas também verificações das condições físicas e higiênicosanitárias de cada ambulante no momento da aquisição das amostras. Para essa avaliação, utilizou-se roteiro de inspeção conforme Felipe e Miguel $^{6}$, do tipo observacional, no qual foram avaliados os manipuladores e as estruturas físicas (Quadro 1).

Quadro 1. Modelo da ficha de avaliação higiênico-sanitária dos manipuladores de caldo de cana. Modificado de Felipe e Miguel ${ }^{6}$.

\begin{tabular}{|c|c|c|}
\hline \multicolumn{3}{|c|}{ AVALIAÇÃO HIGIÊNICO-SANITÁRIA DOS MANIPULADORES } \\
\hline Localização: & Data da cole & \\
\hline \multicolumn{3}{|c|}{ AVALIAÇÃO HIGIÊNICO-SANITÁRIA DOS MANIPULADORES } \\
\hline Usa joia e adornos nas mãos & SIM & NÃO \\
\hline Unhas aparadas e curtas & SIM & NÃO \\
\hline Cabelos protegidos por touca, boné ou rede & SIM & NÃO \\
\hline Usa luvas para manipulação da garapa & SIM & NÃO \\
\hline Quem manipula a garapa manipula o dinheiro & SIM & NÃO \\
\hline Tem local para higienização das mãos & SIM & NÃO \\
\hline $\begin{array}{l}\text { Qual o estado geral do carrinho (quanto à limpeza e } \\
\text { conservação) }\end{array}$ & BOM & RUIM \\
\hline Presença de algum tipo de praga no local & SIM & NÃO \\
\hline
\end{tabular}

Para as análises microbiológicas das amostras, o laboratório utilizou como método a contagem de microrganismos em placa, conforme descrito por Kornacki e Johnson ${ }^{7}$. As amostras foram homogeneizadas, diluídas em série, e semeadas em placas pelo método de profundidade em meio de ágar vermelho violeta bile e incubadas a $36^{\circ} \mathrm{C}$ por $24 \mathrm{~h}$.
A presença de coliformes totais foi confirmada pelo crescimento e formação de gás (mínimo 1/10 do volume total do tubo de Durhan) ou efervescência, quando agitado gentilmente em caldo verde brilhante bile a $35^{\circ} \mathrm{C}$. Após $24 \mathrm{~h}$ de incubação, realizou-se a leitura de todos os tubos, porém, os que apresentaram 
resultado negativo foram reincubados por mais $24 h^{7}$.

Para presença de coliformes termotolerantes, as amostras foram inoculadas em tubos contendo caldo Escherichia coli (EC) e foram incubados a $45 \pm 0,2^{\circ} \mathrm{C}$, por 24 a $48 \mathrm{~h}$. A presença de coliformes termotolerantes foi confirmada pela formação de gás (mínimo 1/10 do volume total do tubo de Durhan) ou efervescência quando agitado gentilmente após $24 \mathrm{~h}$ de incubação. Os tubos negativos permaneceram incubados por mais $24 \mathrm{~h}$ para confirmação da negatividade ${ }^{7}$.

Considerou-se como positivo crescimento superior a $1,0 \times 10^{2} \mathrm{UFC} / \mathrm{ml}$ para coliformes termotolerantes. Para coliformes totais a legislação não define valor de referência. Para análise dos dados e definição se reprovado ou aprovado, observou-se a contagem de UFC/ml acima do valor permitido para coliformes termotolerantes.
Os dados coletados foram armazenados em Microsoft Excel ${ }^{\circledR}$ e para análise e estudo sobre a associação entre variáveis adotou-se o teste de Qui Quadrado $\left(x^{2}\right)$ em nível de significância de $p \leq 0,05$. A análise estatística foi realizada através do software Bioestat ${ }^{\circledR}$.

\section{RESULTADOS}

Os resultados obtidos nos ensaios de avaliação do perfil microbiológico do caldo de cana in natura foram comparados com os padrões estabelecidos pela RDC 12/2001 para pesquisa de coliformes termotolerantes. Observa-se na Tabela 1 que 20 (66,6\%) amostras apresentaram coliformes termotolerantes acima de $1,0 \times 10^{2} \mathrm{UFC} / \mathrm{mL}$, estando em desacordo com a Resolução RDC no 12/2001, quanto aos padrões microbiológicos.

Tabela 1. Análises microbiológicas de coliformes em caldos-de-cana coletados em Cascavel-PR.

\begin{tabular}{|c|c|c|c|}
\hline Amostras & $\begin{array}{c}\text { Coliformes Termotolerantes } \\
\text { (UFC/mL) }\end{array}$ & $\begin{array}{c}\text { Coliformes Totais } \\
\text { (UFC/mL) }\end{array}$ & $\begin{array}{c}\text { Resultado da } \\
\text { análise }\end{array}$ \\
\hline 1 & $6,2 \times 10^{4}$ & $6,2 \times 10^{4}$ & Reprovada \\
\hline 2 & $1,1 \times 10^{5}$ & $3,3 \times 10^{5}$ & Reprovada \\
\hline 3 & $6,6 \times 10^{5}$ & $6,6 \times 10^{5}$ & Reprovada \\
\hline 4 & $1,2 \times 10^{6}$ & $2,3 \times 10^{6}$ & Reprovada \\
\hline 5 & $<1,0 \times 10^{\circ}$ & $1,2 \times 10^{3}$ & Aprovada \\
\hline 6 & $<1,0 \times 10^{\circ}$ & $<1,0 \times 10^{\circ}$ & Aprovada \\
\hline 7 & $<1,0 \times 10^{\circ}$ & $1,9 \times 10^{4}$ & Aprovada \\
\hline 8 & $1,4 \times 10^{4}$ & $1,4 \times 10^{4}$ & Reprovada \\
\hline 9 & $<1,0 \times 10^{1}$ & $2,1 \times 10^{4}$ & Aprovada \\
\hline 10 & $5,4 \times 10^{3}$ & $1,6 \times 10^{4}$ & Reprovada \\
\hline 11 & $2,9 \times 10^{3}$ & $1,8 \times 10^{4}$ & Reprovada \\
\hline 12 & $1,1 \times 10^{5}$ & $1,1 \times 10^{5}$ & Reprovada \\
\hline 13 & $5,5 \times 10^{3}$ & $1,1 \times 10^{4}$ & Reprovada \\
\hline 14 & $9,1 \times 10^{2}$ & $9,1 \times 10^{2}$ & Reprovada \\
\hline 15 & $1,3 \times 10^{3}$ & $1,3 \times 10^{3}$ & Reprovada \\
\hline 16 & $<1,0 \times 10^{1}$ & $4,5 \times 10^{3}$ & Aprovada \\
\hline 17 & $5,4 \times 10^{2}$ & $5,4 \times 10^{2}$ & Reprovada \\
\hline 18 & $1,7 \times 10^{5}$ & $1,7 \times 10^{5}$ & Reprovada \\
\hline 19 & $1,4 \times 10^{5}$ & $1,4 \times 10^{5}$ & Reprovada \\
\hline 20 & $1,2 \times 10^{4}$ & $1,8 \times 10^{4}$ & Reprovada \\
\hline 21 & $<1,0 \times 10^{1}$ & $4,5 \times 10^{3}$ & Aprovada \\
\hline 22 & $1,9 \times 10^{5}$ & $1,9 \times 10^{5}$ & Reprovada \\
\hline 23 & $1,6 \times 10^{4}$ & $1,6 \times 10^{4}$ & Reprovada \\
\hline 24 & $1,5 \times 10^{4}$ & $1,5 \times 10^{4}$ & Reprovada \\
\hline 25 & $<1,0 \times 10^{1}$ & $6,3 \times 10^{3}$ & Aprovada \\
\hline 26 & $7,4 \times 10^{2}$ & $1,1 \times 10^{3}$ & Reprovada \\
\hline 27 & $1,2 \times 10^{4}$ & $1,8 \times 10^{4}$ & Reprovada \\
\hline 28 & $<1,0 \times 10^{1}$ & $7,3 \times 10^{3}$ & Aprovada \\
\hline
\end{tabular}

Colloq Vitae2017 set-dez; 9(3): 07-12. DOI: 10.5747/cv.2017.v09.n3.v203 
Valores de referência da RDC 12, de 2 janeiro de 2001: 1,0X10² para coliformes termotolerantes; sem valores de referência para coliformes totais.

Tendo por base as observações realizadas nos pontos de venda de caldo de cana, a qualidade higiênico-sanitária desse tipo de comércio é insatisfatória. Foi alto o percentual de vendedores que não utilizavam proteção para os cabelos $(36,6 \%)$, luvas $(83,4 \%)$, desprezavam o bagaço da cana no chão ou em lixo sem tampa, manipulavam o caldo e dinheiro ao mesmo tempo $(93,4 \%)$ e raramente preocupavam-se em lavar as mãos (Tabela 2).

Tabela 2. Resultado da avaliação higiênico-sanitária, segundo Ficha de avaliação criada pelos autores e aplicada aos manipuladores. Cascavel-PR, 2015.

\begin{tabular}{lccc}
\hline \multicolumn{1}{c}{ Itens Avaliados } & Sim & Não & p \\
& $\mathrm{n}(\%)$ & $\mathrm{n}(\%)$ & \\
\hline Uso de joias e adornos nas mãos & $2(6,6)$ & $28(93,4)$ & $<0,0001$ \\
Unhas aparadas e curtas & $29(96,6)$ & $1(3,4)$ & $<0,0001$ \\
Cabelos protegidos por touca, boné ou rede & $19(63,4)$ & $11(36,6)$ & 0,14 \\
Usa luvas para manipulação da garapa & $5(16,6)$ & $25(83,4)$ & 0,0003 \\
Quem manipula a garapa manipula o dinheiro & $28(93,4)$ & $2(6,6)$ & $<0,0001$ \\
Qual o estado geral do carinho & $9(30)$ & $21(70)$ & 0,03 \\
Presença de algum tipo de praga no local & $9(30)$ & $21(70)$ & 0,03 \\
Local para higienização das mãos & $30(100)$ & $0(0)$ & $<0,0001$ \\
\hline
\end{tabular}

\section{DISCUSSÃO}

No presente estudo, foi verificado que $66,6 \%$ (20/30) das amostras analisadas apresentaram crescimento microbiano acima do preconizado para coliformes termotolerantes. Embora essa quantidade não tenha se mostrado estatisticamente significativa $(p=0,06)$ em relação às amostras que apresentaram crescimento dentro do esperado (10/30), é uma frequência muito elevada quando se considera a quantidade de pessoas que consomem a bebida.

Em Salvador-BA foi realizado um trabalho com 30 amostras de caldo de cana colhidas no comércio ambulante da cidade, dentre essas, 23 foram consideradas inadequadas para 0 consumo, pois apresentaram coliformes fecais acima dos limites estabelecidos pela legislação vigente, seis apresentaram contagens acima do permitido para Estafilococos coagulase positiva, indicando perigo de produção de toxina e risco de intoxicação alimentar ${ }^{8}$. Já em Belo HorizonteMG foram avaliadas 20 amostras de caldo de cana in natura comercializadas nas lanchonetes da cidade. Verificou-se que 10 amostras (50\%) apresentaram altas contagens de coliformes totais (> $1100 \mathrm{NMP} / \mathrm{mL}$ ), 7 (35\%) apresentaram algum grau de contaminação por coliformes à $45^{\circ} \mathrm{C}$ (dentro dos limites estabelecidos pela RDC 12 - para a amostra representativa é de até $1,0 \mathrm{x}$ $\left.10^{2}\right), 4(20 \%)$ apresentaram contaminação por $E$. coli e nenhuma mostrou presença de Salmonella $\mathrm{spp}^{9}$. Também em análise realizada em Itumbiara-GO, onde foi avaliada a quantidade microbiológica de 5 amostras de caldo de cana em triplicata, foi constatada a presença de coliformes totais em todas as amostras (100\%) e destas, três apresentaram coliformes termotolerantes (20\%), ambos em inconformidade com a resolução ${ }^{6}$.

Rodrigues et al. ${ }^{10}$ avaliaram a qualidade microbiológica do caldo de cana quanto à determinação de coliformes totais e coliformes termotolerantes em Teresina-PI, e verificaram que $100 \%$ dessas amostras apresentaram valores impróprios para o consumo de acordo com a RDC 12 , que estabelece valor máximo para coliformes a $45^{\circ} \mathrm{C}$ de $10 \mathrm{NMP} / \mathrm{mL}$. Contrapondo-se a isso, em Curitiba-PR, foi avaliada a qualidade microbiológica de 30 amostras de caldo de cana e verificou-se que $29(96,6 \%)$ apresentaram padrão microbiológico satisfatório. Porém, observou-se que os comerciantes utilizavam diversos procedimentos inadequados de higiene ${ }^{3}$. Já na cidade paulista de Ribeirão Preto, avaliou-se a qualidade microbiológica de 90 amostras e dessas, 28 (31,1\%) apresentaram coliformes a $45^{\circ} \mathrm{C}$ acima de $2 \log \mathrm{NMP} / \mathrm{mL}^{11}$. 
Santos et al. ${ }^{12}$ coletaram 32 amostras do caldo de cana em quatro estabelecimentos ambulantes na cidade de Tangará da Serra-MG, nos meses de junho e julho de 2009. As coletas foram realizadas semanalmente, sendo quatro amostras para cada local, totalizando 16 amostras/mês. Todas as amostras analisadas apresentaram coliformes totais (100\%) e quatro (12\%) destas apresentaram coliformes termotolerantes. Já em Umuarama-PR foram analisados coliformes totais e coliformes termotolerantes de 24 amostras, sendo que, 14 $(58,3 \%)$ estavam em desacordo com a RDC $12 / 2001^{13}$.

Com relação às condições higiênicosanitárias, embora tenha sido verificado que $100 \%$ dos ambulantes apresentem local para higienização das mãos, essa prática nem sempre é realizada, e $93,4 \%$ dos ambulantes manipulam cana e dinheiro sem a higienização adequada das mãos. Verificou-se também que $36,6 \%$ dos manipuladores não usam touca, boné ou rede para proteger os cabelos, propiciando a contaminação pela queda dos mesmos dentro do alimento. Embora, a luva seja de grande importância em alguns momentos, pode se tornar um grave problema quando utilizada na manipulação de alimentos, devido a alguns manipuladores não retirarem a mesma independente do que estão manipulando, isso é, dinheiro ou cana-de-açúcar. Foi verificado que $16,6 \%$ dos manipuladores não fazem utilização de luvas durante a preparação do caldo de cana.

Segundo Prati et al. $^{14}$ a grande carga microbiana presente no caldo de cana é atribuída a uma série de falhas higiênico-sanitárias, como a manipulação do caldo de cana e do dinheiro, uso de panos sujos, roupas e unhas sujas, falta de toucas e luvas e presença de pragas, medidas estas que propiciam a contaminação por microrganismos. Oliveira et al. $^{15}$ também constataram várias deficiências nas condições de comércio do caldo de cana. Neste estudo, os autores desenvolveram e aplicaram um check-list a 70 vendedores ambulantes de caldo de cana e confirmaram ausência de capacitação profissional eficiente entre a maioria dos manipuladores, infraestrutura geralmente inadequada e pouco conhecimento sobre cuidados higiênicosanitários a serem utilizados para garantir a boa qualidade do produto disponibilizado ao consumidor.
Em estudo realizado em Ponta Grossa-PR foram avaliados 24 pontos de venda. Como metodologia, utilizou-se uma ficha de verificação, elaborada segundo modelo da Vigilância Sanitária. Os aspectos considerados incluíram condições da infraestrutura, equipamentos e utensílios, manipuladores e produção do alimento. Com base nos conceitos a pesquisa revelou os seguintes resultados em relação à Infraestrutura: $20,8 \%$ péssimo; $70,8 \%$ ruim e 8,4\% regular; Equipamentos e utensílios: $45,8 \%$ ruim; $12,5 \%$ regular e $41,4 \%$ bom; Manipuladores: $16,7 \%$ péssimo; $70,8 \%$ ruim e 12,5\% regular; Produção do alimento: $41,7 \%$ ruim; $41,7 \%$ regular e $16,6 \%$ bom. Quanto às condições gerais dos pontos de venda, os valores encontrados foram: $75 \%$ ruim; $20,8 \%$ regular e $4,2 \%$ bom, não se constatando pontuação para a classificação excelente ${ }^{16}$.

Em conclusão, das 30 amostras de caldo de cana comercializadas em Cascavel-PR, provenientes de diferentes bairros do município, verificou-se que $66,6 \%$ apresentavam-se fora do preconizado pela legislação vigente quanto à presença de bactérias, o que se mostra semelhante aos demais estudos realizados em outras regiões do país. Esses resultados confirmam a necessidade da conscientização por parte dos manipuladores, já que também foram verificadas condições insatisfatórias na manipulação da cana-de-açúcar e do caldo da cana, além de servir como alerta aos órgãos fiscalizadores sobre as condições do comércio ambulante, aliando-se a fiscalização ativa e ações de educação sanitária ${ }^{3}$.

\section{REFERÊNCIAS}

1. Carvalho FAL, Molinari RF, Condé JG, Lopes CL, Oliveira MFF, Rodrigues FC. Avaliação preliminar da qualidade microbiológica do caldo de cana comercializado por ambulantes na cidade de Viçosa, MG, Brasil. Anais III SIMPAC, Viçosa-MG. 2011. p.146-51.

2. Marques MO. Tópicos em Tecnologia Sucroalcooleira. Jaboticabal: Multipress; 2006. $191 p$.

3. Lopes G, Cresto R, Marron Carraro CN. Análise microbiológica de caldos de cana comercializados nas ruas de Curitiba-PR. Hig Alimentar. 2004;20(147): 40-44.

4. Brasil. Ministério da Saúde. Agência Nacional de Vigilância Sanitária (ANVISA). Resolução da 
Diretoria Colegiada (RDC) no 12, de 10 de janeiro de 2001.

5. Instituto Brasileiro de Geografia e Estatística (IBGE), Diretoria de Pesquisas (DPE), Coordenação de População e Indicadores Sociais (COPIS). 2015. Acesso: 28 janeiro 2017. Disponível: http://cidades.ibge.gov.br/xtras/perfil.php?codmu $\underline{\mathrm{n}=410480}$.

6. Felipe LM, Miguel DP. Análise da qualidade microbiológica do caldo de cana. Cad Pós-Grad Fazu. 2011;8:77-82.

7. Kornacki JL, Johnson JL. Enterobacteriaceae, coliforms, and Escherichia coli as quality and safety. In: Downes FP, Ito K. Compendium of methods for the microbiological examination of foods. 4.ed. , 2013. DOI: https://doi.org/10.2105/9780875531755ch08

8. Leite CC, Sousa LS, Braga AV, Assis PN, Rêgo FLT. Perfil microbiológico do caldo de cana comercializado em Salvador. Hig alimentar. 2003;17:94.

9. Oliveira KCD. Análise microbiológica dos caldos de cana comercializados em lanchonetes de Belo Horizonte. [Monografia]. Especialização em Microbiologia Ambiental e Industrial. Departamento de Microbiologia do Instituto de Ciências Biológicas. Universidade Federal de Minas Gerais. Belo Horizonte. 2009.

10. Rodrigues AMD, Ferreira LCRP, Lima NA, Muratori MCS. Avaliação microbiológica do caldo de cana comercializado no centro de Teresina-PI. 2007. Acesso: 28 janeiro 2017. Disponível: http://www.sovergs.com.br/site/higienistas/trabalho s/10400.pdf

11. Prado SPT, Bergamini AMM, Ribeiro EGA, Castro MCS, Oliveira MA. Avaliação do perfil microbiológico e microscópico do caldo de cana in natura comercializado por ambulantes. Rev Inst Adolfo Lutz. 2009;69(1):55-61.

12. Santos CP, Ferreira AFN, Carvalho IF, Carvalho MLS. Avaliação preliminar da qualidade microbiológica do caldo de cana consumido na cidade de Tangará da Serra-MT. In: Anais da 2a Jornada Científica da Unemat, 5 e 6 de outubro de 2009. Universidade do Estado do Mato Grosso. Barra do Bugres-MT. 2009

13. Gandra EA, Reitembach AF, Bolanho BC, Guimarães JS, Ganddra TKV. Condições Microbiológicas de caldos de cana comercializados em Umuarama-PR. Rev Bras Tecnol Agroindustr. 2007;1(2):61-9. DOI: https://doi.org/10.3895/S1981$\underline{36862007000200007}$
14. Prati P, Moretti RH, Cardello HMAB, Gândara ALN. Estudo da vida de prateleira de bebida elaborada pela mistura de garapa parcialmente clarificada estabilizada e suco natural de maracujá. B CEPPA. 2004;22(2):295-310.

https://doi.org/10.5380/cep.v22i2.1196

15. Oliveira ACG, Nogueira FAG, Zanão CFP, Souza CW, Spoto MHF. Análise das condições do comércio de caldo de cana em vias públicas de municípios paulistas. Segur Alimentar Nutricional. 2006;13(2):616.

16. Mallon C, Bortozolo EAFQ. Alimentos comercializados por ambulantes: uma questão de segurança alimentar. UEPG Ciênc Biol Saúde. 2004;10(4):65-76.

Recebido para publicação em 01/06/2016

Revisado em 16/06/2017

Aceito em 22/03/2018 